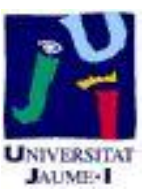

Título artículo / Títol article: Cerebellar hallmarks of conditioned preference for cocaine

\begin{tabular}{ll}
\hline & María Carbó-Gas \\
Autores / Autors & Dolores Vázquez-Sanromán \\
& Isis Gil-Miravet \\
& Joan De las Heras-Chanes \\
& Genaro A. Coria-Ávila \\
& Jorge Manzo \\
Carla Sanchis-Segura \\
Marta Miquel
\end{tabular}

Revista:

Physiology \& Behavior 132 (2014) 24-35

Versión / Versió: $\quad$ Pre-print

Cita bibliográfica / Cita bibliogràfica (ISO 690):
CARBO-GAS, Maria, et al. Cerebellar hallmarks of conditioned preference for cocaine. Physiology \& behavior, 2014, vol. 132, p. 24-35. 


\section{Cerebellar hallmarks of conditioned preference for cocaine}

*Maria Carbo-Gas ${ }^{1}$; *Dolores Vazquez-Sanroman ${ }^{1}$, Isis Gil-Miravet ${ }^{1}$; Joan De las HerasChanes $^{1}$; Genaro A Coria-Avila ${ }^{2}$;orge Manzo $^{2}$; Carla Sanchis-Segura ${ }^{1}$; Marta Miquel ${ }^{1}$

${ }^{1}$ Área de Psicobiología, Universitat Jaume I, Castellon de la Plana, Spain

${ }^{2}$ Centro de Investigaciones Cerebrales. Universidad Veracruzana, Xalapa, Mexico

* Equal contribution

Corresponding author: Marta Miquel Ph.D.

Área de Psicobiologia. Universidad Jaume I. Avenida Sos Baynat s/n. 12071 Castellón, Spain. Phone number:+34 696440177.miquel@psb.uji.es

\section{Conflict of Interest (COI) Statement}

The authors of the present manuscript declare no conflict of interest. 


\section{Abstract}

Pavlovian conditioning tunes the motivational drive of drug-associated stimuli, fostering the probability of those environmental stimuli to promote and trigger drug seeking and taking. Interestingly, different areas in the cerebellum are involved in the formation and longlasting storage of Pavlovian emotional memory. Very recently, we have shown that conditioned preference for an odour associated with cocaine was directly correlated with cFOS expression in cells at the dorsal region of the granule cell layer of the cerebellar vermis. The main goal of the current investigation was to further extend the description of cFOS-IR patterns in cerebellar circuitry after training mice in a cocaine-odour Pavlovian conditioning procedure, including now the major inputs (the inferior olive and pontine nuclei) and one of the output nuclei (the medial deep nucleus) of the cerebellum. The results showed that the cerebellar hallmark of preference towards an odour cue associated to cocaine is an increase in cFOS expression in the dorsal part of the granule cell layer. cFOSIR levels expressed in the granule cell layer of mice that did not show cocaine conditioned preference did not differ from the basal levels. Remarkably, mice subjected to a random cocaine-odour pairing procedure (the unpaired group) exhibited higher cFOS-IR in the inferior olive, the pontine nuclei and in the deep medial nucleus. Therefore, our findings suggest that inputs and the output of cerebellar circuitry are enhanced when contingency between the CS+ and cocaine is lacking.

Keywords: cocaine, cerebellum, mice, Pavlovian conditioning, cFOS. 


\section{Introduction}

Long-lasting storage of drug related memories have been revealed as one of the key processes that contribute to orienting the organism response towards drug-related stimuli [1-4]. Particularly, Pavlovian conditioning tunes the motivational drive of drug-associated stimuli, fostering the probability of those environmental stimuli to promote and trigger drug seeking and taking [1]. Previous studies have strongly suggested that drug-cue associative memories are stored and reactivated by dopamine-glutamate interactions in the basal ganglia, basolateral amygdala, hippocampus and prefrontal cortex $[5,6]$. Interestingly, different areas in the cerebellum are involved in the formation and long-lasting storage of Pavlovian emotional memory $[7,8]$.

Remarkably, increasing evidence has demonstrated close anatomical and functional relationships between the cerebellum and the prefrontal-striatal-limbic networks [9-18]. Both cerebellar-striatal and cerebellar-prefrontal connectivity are bidirectional, forming reciprocal prefrontal-midbrain-cerebellar loops. Importantly, dopamine-glutamate interactions have also been described in the cerebellum $[9,10,13,15,19,20]$. Recently, we have shown that conditioned preference towards an odour associated with cocaine was directly correlated with cFOS expression in cells at the dorsal region of the granule cell layer of the cerebellar vermis [21]. These findings are coincident with those of some clinical reports. In human cocaine addicts, cerebellar activations during exposure to drug-associated cues have been found [22-26]. These findings challenge the conventional perspective of the cerebellum as a subcortical isolated motor structure and they would suggest its involvement in functional networks affected by addictive drugs [27].

In the present study, we aimed at further extending our previous description of neuronal activity patterns in cerebellar circuitry (through cFOS-IR) after training mice in a cocaine-associated odour cue conditioning. Thus, in this case we included the two major inputs to the cerebellum (the olivary complex and pontine nuclei) and the output of the vermis (the deep medial nucleus) in order to suggest an initial picture of the cerebellar hallmarks of conditioned preference for cocaine. 


\section{Methods}

\subsection{Subjects}

Three-week-old Swiss male mice were purchased from Janvier (ST Berthevin Cedex, France) and maintained in the colony room (Universitat Jaume I, Spain) for 30 days prior to experiments. Handling was carried out daily for 5 minutes before experiments began. The colony room was kept at $22 \pm 2^{\circ} \mathrm{C}$ with lights on from 08:00 to 20:00 hours. Animals were housed in standard conditions with laboratory rodent chow and tap water ad libitum. At the age of 7 weeks, experimental procedures began. Behavioural tests were conducted within the first 5 hours of the light cycle. All animal procedures were performed in accordance with the European Community Council directive (86/609/ECC), Real Decreto 1201/2005 and the local directive DOGV 13/2007. Of the total number of 51 mice involved in the behavioural protocols 21 were used for the purposes of determining cFOS activity in the cerebellum.

\subsection{Pharmacological agents}

All drugs were administered intraperitoneally (i.p.). Cocaine hydrochloride (Alcaliber S.A., Madrid, Spain) was dissolved in $0.9 \%(\mathrm{w} / \mathrm{v})$ saline $(2 \mathrm{mg} / \mathrm{ml})$ and injected immediately before each conditioning trial. Saline solution $0.9 \%(\mathrm{w} / \mathrm{v})$ was used as the vehicle control.

\subsection{Behavioural procedures and experimental design}

Two equally preferred odours (lavender and strawberry) [21] were used as conditioned stimuli in the present study. A gauze was scented with four drops of lavender or strawberry fragrance and presented inside a steel ball with holes, which overhung on one of the maze arms walls. One of the odours acted as CS+ and was associated to cocaine $(20 \mathrm{mg} / \mathrm{kg}$, IP). On alternate days, mice were exposed to the other odour (CS-) and received saline injections. These pairing sessions lasted for 15 minutes and took place in a specific conditioning environment (a rectangular plastic box of $30 \times 15 \times 20 \mathrm{~cm}$ ). A total of 8 cocaine-paired sessions were conducted 
using an $\mathrm{ABAB}$ design and the odours used as $\mathrm{CS}+$ and $\mathrm{CS}_{-}$were counterbalanced between animals. Additionally, we included two control groups: The so-called "unpaired group", which was composed of animals receiving the same number of cocaine injections but randomly associated to the odours and the "saline group" including mice that were subjected to the same conditioning sessions but received saline in all of them. Preference was evaluated 48 hours after the last cocaine administration in a 30-minute drug-free test using a T-maze in which $\mathrm{CS}+$ and CS- odours were present simultaneously but in opposite arms. Time spent in each arm was automatically registered. All test sessions were videotaped and the time spent (TS) in each arm of the maze was registered manually from the recorded test sessions during the last 20 minutes by a blind observer. Preference score was calculated as $\left[\mathrm{TS}\right.$ in $\mathrm{CS}+/\left(\mathrm{TS}\right.$ in $\mathrm{CS}^{+}+\mathrm{TS}^{-}$in $\left.\left.\mathrm{CS}^{-}\right)\right] \mathrm{x}$ 100.

\subsection{Perfusion protocol and tissue sections}

Animals were deeply anesthetized with sodium pentobarbital $(30 \mathrm{mg} / \mathrm{kg}) 70$ minutes following the preference test and perfused transcardially, first with $0.9 \%$ saline solution and then with $4 \%$ paraformaldehyde. After perfusion, the brainstem and the cerebellum were quickly dissected and placed in a container with $4 \%$ paraformaldehyde for 24 hours. After this time, tissue was cryoprotected in $30 \%$ sucrose solution until complete immersion.

Brain tissue was rapidly frozen by immersion in liquid nitrogen and sections were performed at $40 \mu \mathrm{m}$ with a cryostat microtome (Microm HM560, Thermo Fisher Scientific, Barcelona, Spain). Six series of tissue sections were collected and stored at $-80^{\circ} \mathrm{C}$ in cryoprotectant solution. Sagittal sections of the cerebellum and the brainstem were selected according to the lateral coordinates from $-0.04 \mathrm{~mm}$ to $0.72 \mathrm{~mm}$, comprising the vermis cerebellum, the medial cerebellar nucleus, the inferior olive and the pontine nuclei [28].

\section{5.cFOS Immunohistochemistry}

Immunohistochemistry was performed on free-floating sections. For peroxidative immunostaining, tissue peroxidases were eliminated with $0.3 \%$ of $\mathrm{H}_{2} \mathrm{O}_{2}$ and methanol $20 \%$, 
during a period of 30 minutes. Tissue was incubated for 48 hours with a polyclonal primary antibody, rabbit anti-cFOS (1:500; Santa Cruz Biotechnology, Santa Cruz, CA, USA) in smooth agitation at $4^{\circ} \mathrm{C}$. In a second step, sections were exposed to an affinity-purified secondary biotinylated antibody, donkey anti-rabbit (1:400; BA-2000; Vector Laboratories, Inc., Burlingame, CA, USA) for 120 minutes at room temperature. For magnification, we used preassembled biotin-avidin peroxidase complex according to the Vector Labs recommendations (ABC Elite; Vector Laboratories). Sections were exposed to DAB solution free of nickel component until the tissue developed an intense brown staining, then the tissue was rinsed and mounted.

\subsection{Immunostaining Analysis}

Images were captured in an optic microscope (Nikon E-800, Izasa Werfen Group, Valencia, Spain) with 20x or 40x lenses. We considered cFOS+ those cells exhibiting a uniform and constant brown labelling in the nucleus (see Figure 1,2).

We counted the first plane of three sagittal sections at the granule cell layer of the vermis cerebellum (L -0.04 to $0.72 \mathrm{~mm}$ ) at the dorsal and medial zone of each cerebellar lobule [28], in selected regions of interest (ROIs) of $20,000 \mu \mathrm{m}^{2}$ for a total area of $40,000 \mu \mathrm{m}^{2}$ per lobule. Purkinje neurons were estimated in an area of $80,000 \mu \mathrm{m}^{2}$ in the dorsal and ventral regions, for a total area of $160,000 \mu \mathrm{m}^{2}$ per lobule. The ROI for the medial nucleus was $80,000 \mu \mathrm{m}^{2}$. For the olivary complex, ROIs were $20,000 \mu \mathrm{m}^{2}$ of the dorsal, ventral and medial parts for a total area of $60,000 \mu \mathrm{m}^{2} . \mathrm{cFOS}+$ neurons in the pontine nuclei were considered in an area of 40 $000 \mu \mathrm{m}^{2}$. Cell count was performed automatically with FIJI (1.47h; NIH) software by properly identifying every cFOS+ cell. 


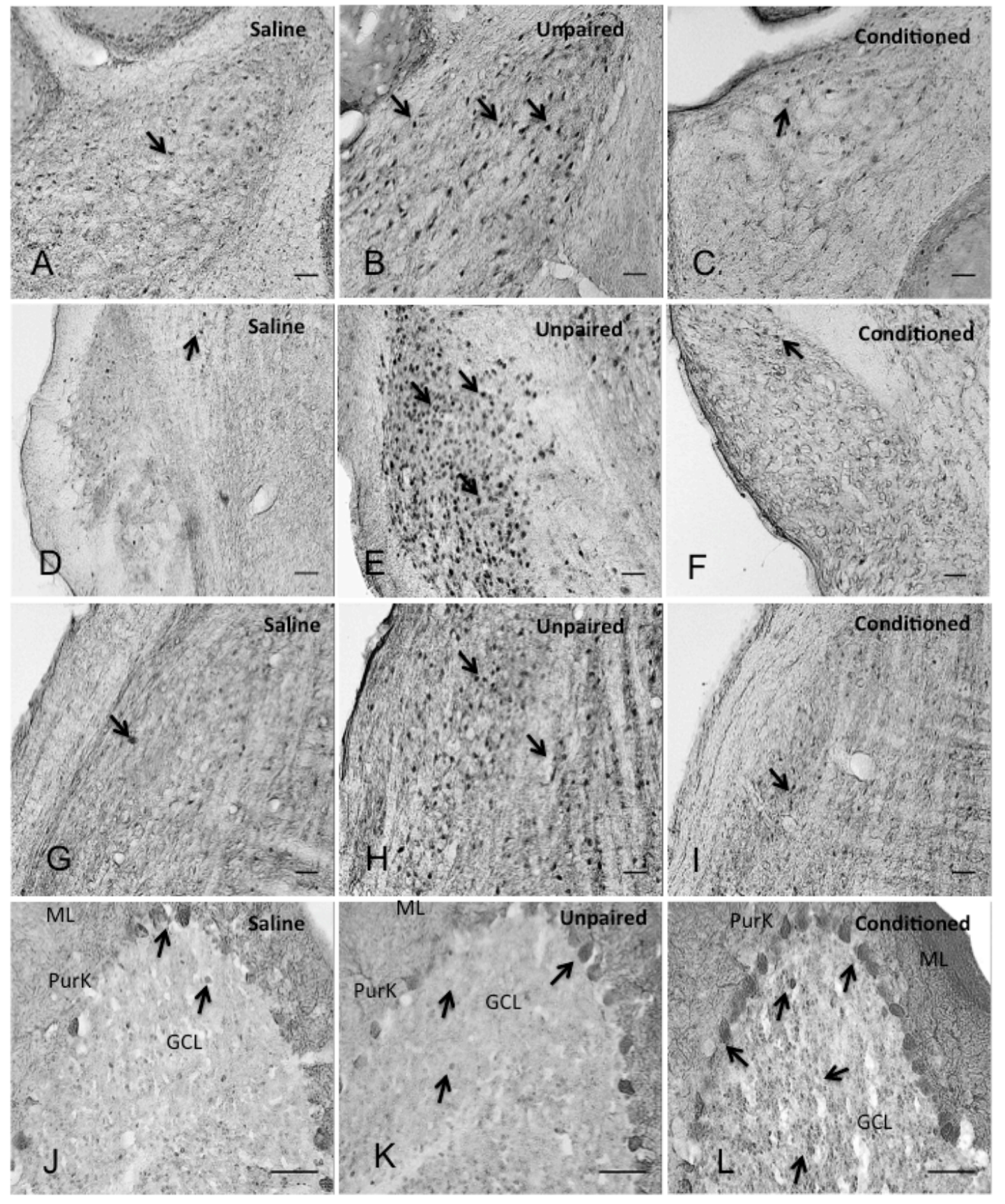

Figure 1. Representative microphotographs of cFOS-IR in mice from the saline, conditioned and unpaired groups. The medial nucleus of the cerebellum (A, B, C); the pontine nucleus (D, E, F); the Inferior Olive (G, H, I) and the cerebellar cortex (J, K, L). Arrows indicate examples of cFOS+ cells. ML: molecular layer; PurK: Purkinje neurons; GCL: granule cell layer. Scale bar: $50 \mu$. 


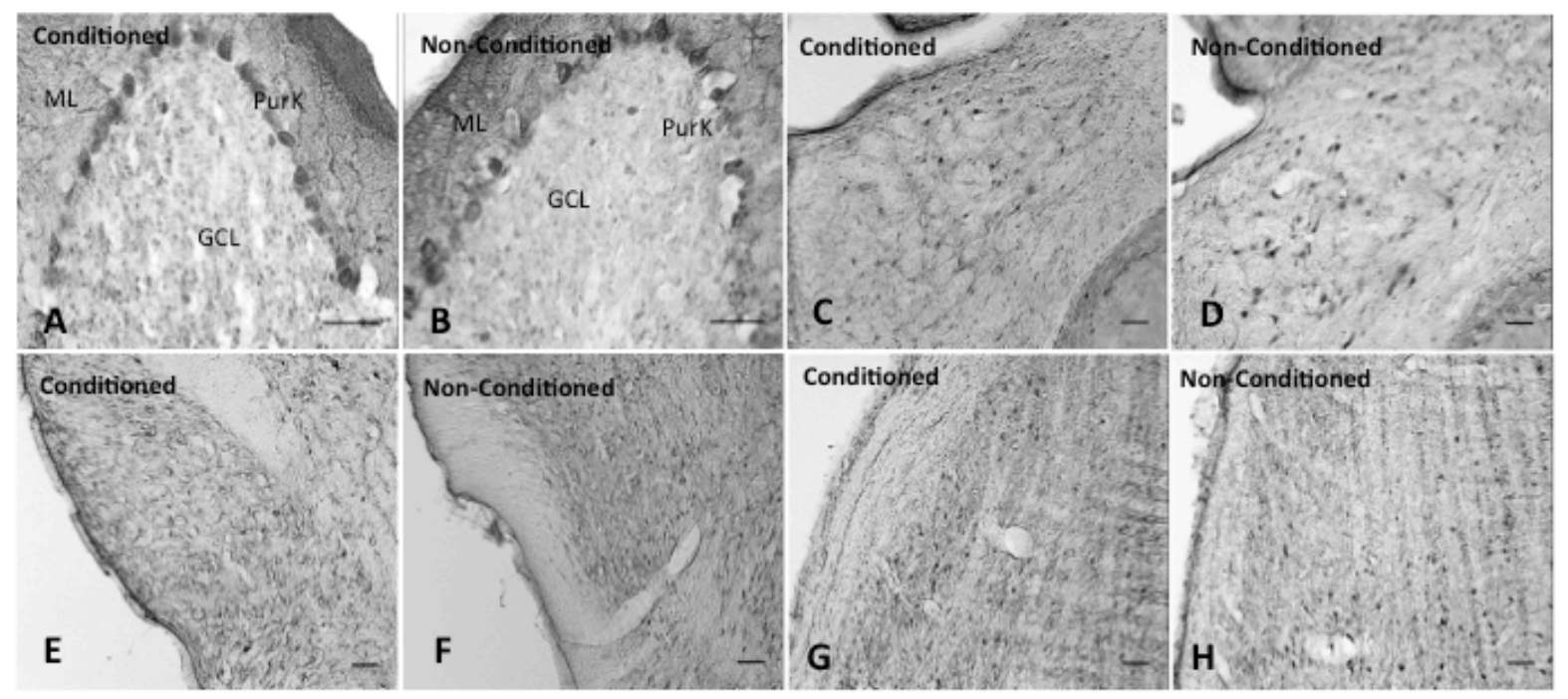

Figure 2. Representative microphotographs of cFOS-IR from the conditioned and nonconditioned mice. The granule cell layer (A, B); the medial nucleus of the cerebellum (C, D); the pontine nucleus $(\mathrm{E}, \mathrm{F})$ and the Inferior Olive $(\mathrm{G}, \mathrm{H})$. ML: molecular layer; PurK: Purkinje neurons; GCL: granule cell layer; WM: white matter. Scale bar: $50 \mu$.

\subsection{Statistics}

Data presented as mean \pm SEM were analysed by one-way ANOVAs or Student t-tests using the treatment group as the comparison factor. Follow-up comparisons if necessary were conducted by Fisher's LSD tests. Statistical level of significance was set at $\mathrm{p}<0.05$.

Although it is not a common practice in this kind of studies, by calculating the Cohen's $d$ statistic (and corresponding confidence intervals), we estimated the effect size for each and every dyadic comparison of means that yielded statistical significance. The reporting of effect sizes facilitates the interpretation of the substantive, as opposed to the statistical significance of empirical results, then complementing the conclusions drawn from inferential statistics based on the rejection of the null hypothesis at a particular $p$ value [29]. In this way, we were able to provide information about the magnitude of the effects of interest as well as about the precision on these estimates. Finally, we analysed the pattern of intercorrelations among the cFOS levels at different cerebellar anatomical sites of interest. These correlations were calculated on the percentual increases/ decreases on cFOS levels over saline and estimated by means of the non- 
parametric Spearman's Rho index, which does not incorporates an a priori assumption of a linear (but just a monotonic) relationship between the variables of interest.

\section{Results}

\subsection{Preference for cocaine-paired odour cue}

A one-way ANOVA comparing the preference for the CS+ yielded a significant effect for the experimental group $\left(\mathrm{F}_{2,18}=7,44, \mathrm{p}<0.01\right)$. As revealed by subsequent posthoc comparisons the contingently trained group (the paired group) $(n=10)$ exhibited significantly higher preference $(\mathrm{p}<0.01$ in both cases) for the maze arm containing the $\mathrm{CS}+$ than the unpaired $(\mathrm{n}=6)$ and saline $(n=5)$ groups, which did not differ among them (Figure 3A).

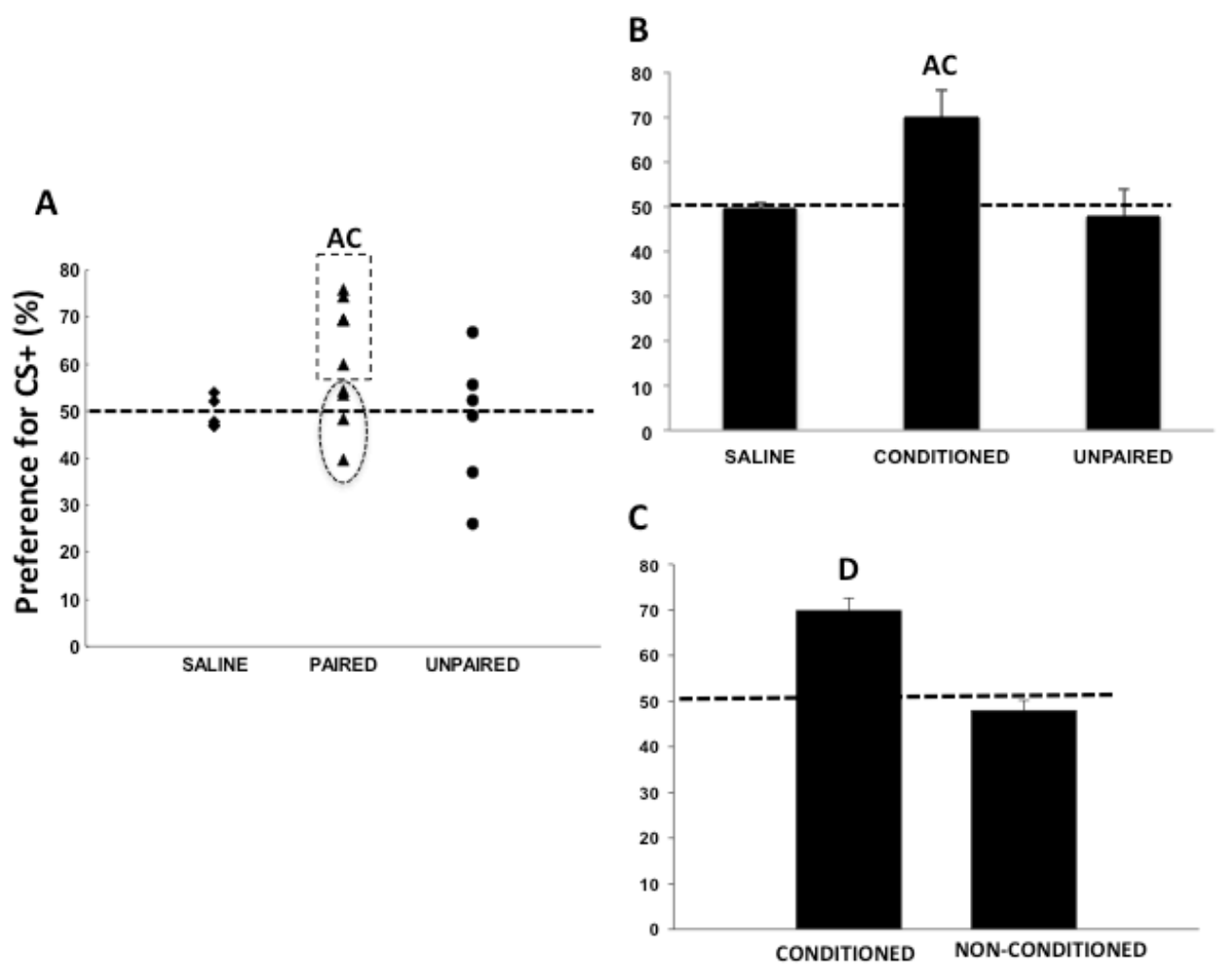

Figure 3. (A) Scatterplot of cocaine-induced odour preference score in the three experimental groups. (B) Percentage of preference for cocaine-associated odour-cue on the test day in thesaline, conditioned and unpaired groups. (C) Percentage of preference for cocaine-associated odour-cue in the conditioned and non-conditioned groups. Data are shown as mean $\pm(\mathrm{SEM})$ of preference on the test day in each treatment group. Capital letters indicate a significant 
difference $(\mathrm{p}<0.01)$ towards the saline $(A)$, unpaired group (C) or non-conditioned (D), respectively.

However, as it can be observed in the scatterplot (Figure 3A), not all subjects receiving cocaine injections paired with the CS+ exhibited a preference score higher than the indifference point (50\%). Therefore, we used an arbitrary cut-off preference score of $60 \%$ to split this group into two subgroups "conditioned" $(\mathrm{n}=5)$ and "non-conditioned" $(\mathrm{n}=5)$. Then in a first step, we accomplished comparisons between the saline, conditioned and unpaired groups. As expected, a new one-way ANOVA yielded a significant effect of the experimental group $\left(\mathrm{F}_{2,13}=8.24\right.$, $\mathrm{p}<0.01)$. Post-hoc based tests revealed that the conditioned group exhibited a higher preference for the arm containing the CS+ than the unpaired and saline groups ( $p<0.01$ in both cases). These results are displayed in Figures 3A, B.

As there was a subgroup of animals that in spite of being trained under contingent odourcocaine associations never developed preference for $\mathrm{CS}+$, in a second step we addressed the comparison between these two groups (the conditioned and non-conditioned group) by means of Student t-test for independent samples. As expected, the Student t-test showed a significant higher preference score in the conditioned group as compared to the non-conditioned group $\left(\mathrm{T}_{8}=4.80, \mathrm{p}<0.02\right)$ (Figure 3C).

We also addressed a one-way ANOVA to evaluate to what extent locomotion displayed during the preference test could be one of the relevant variables in order to explain between-group differences. Any of the four groups differed significantly from each other $\left(\mathrm{F}_{3,17}=0.18 ; \mathrm{p}=0.47\right)$. Mean and standard error of $\mathrm{cm}$ in 30 minutes were as follow: the saline group $=12472 \pm 2691$; the conditioned group $=8276 \pm 2105 ;$ the non-conditioned group $=8861 \pm 795 ;$ the unpaired group $=9851 \pm 1718$.

\section{2.cFOS-IR in the granule cell layer}

First, we examined cFOS expression in several cerebellar regions of the three experimental groups. We were able to replicate our previous findings [21] indicating selective changes on the level of cFOS-IR in the dorsal and the ventral regions of the granule cell layer of the vermis 
cerebellum (see Figure 4A, B, D, E, G, H) (tables 1 and 2 for further details). More specifically, a series of one-way ANOVAs confirmed a group effect on the number of cFOS+ cells in the dorsal region of all lobules ( $\mathrm{p}<0.01$ in all cases, see table 1 for further details). As expected, post-hoc comparisons revealed that this effect was driven by a significant increase in cFOS staining levels in the conditioned group as compared to the saline and unpaired groups, which had a similar number of $\mathrm{cFOS}+$ cells ( $\mathrm{p}<0.01$ in all cases). In lobes VII and VIII, differences between the conditioned and the unpaired group were additionally boosted by a statistically significant reduction on cFOS expression in the unpaired group, falling below that of the saline group ( $p<0.05$ in both cases). On the other hand, a second series of one-way ANOVAs demonstrated a group effect on the cFOS-IR in the ventral region of all vermal lobules. In this case, between-group differences were achieved by a generalized reduction of cFOS levels in the unpaired group, which was statistically significant $(\mathrm{p}<0.01)$ in all lobules except in lobule $\mathrm{V}$ ( $>0.05$ in this case). Also in this lobule, the conditioned group exhibited a significant increase in cFOS + cells towards the saline group $(\mathrm{p}<0.05)$.

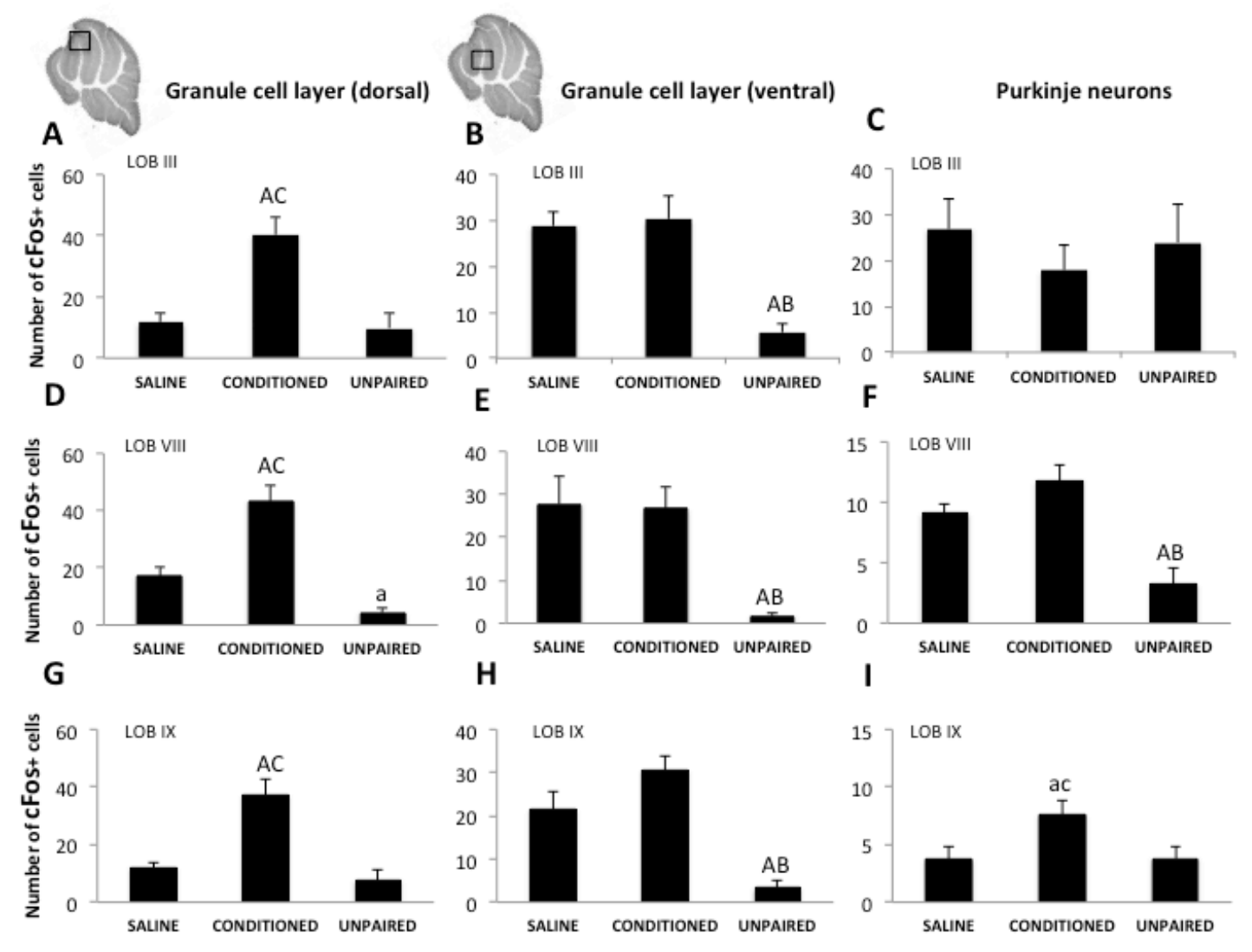


Figure 4. cFOS-IR in different areas of the cerebellar cortex Lobules III (A, B, C), VIII (D, E, F) and IX (G, H, I) of the saline, conditioned and unpaired groups. Panels depict mean $\pm($ SEM) of the number of cFOS+ neurons in the dorsal $(A, D, G)$ and ventral $(B, E, H)$ regions of the granule cell layer. Panels $(C, F, I)$ represent mean $\pm(S E M)$ of cFOS+ Purkinje cells. Capital letters indicate a significant difference $(\mathrm{p}<0.01)$ towards the saline $(A)$, conditioned $(B)$, or unpaired group $(C)$, respectively. Minor letters indicate a significant difference $(p<0.05)$ towards the saline (a), conditioned (c) or unpaired group (c), respectively.

Next, we addressed a further exploration into the cerebellar signatures of drug-induced preference memory by assessing cFOS expression in conditioned animals as compared to nonconditioned ones (Figure 5). When conditioned preference for cocaine was not expressed, the dorsal region of the granule cell layer showed significant lower cFOS-IR levels in lobules II $\left(\mathrm{T}_{8}=3.00, \mathrm{p}<0.02\right) ; \mathrm{III}\left(\mathrm{T}_{8}=4.06, \mathrm{p}<0.005\right) ; \mathrm{V}\left(\mathrm{T}_{8}=3.96, \mathrm{p}<0.006\right) ; \mathrm{VI}\left(\mathrm{T}_{8}=3.26, \mathrm{p}<0.02\right) ; \mathrm{VIII}$ $\left(\mathrm{T}_{8}=3.38, \mathrm{p}<0.02\right) ; \mathrm{IX}\left(\mathrm{T}_{8}=2.86, \mathrm{p}<0.03\right) ; \mathrm{X}\left(\mathrm{T}_{8}=3.49 ; \mathrm{p}<0.02\right)$. Rather, in the ventral region of the granule cell layer cFOS expression was similar in either of two groups trained under contingency.

Therefore, it appears that at the level of the granular layer the signature of conditioned preference for cocaine is a higher activity in those neurons in the dorsal region. As we also showed in a previous study [21], ventral regions of the granular layer seem to represent contingency between stimuli rather than emotional memory associated to the drug, because it is the unpaired group which are those exhibiting less activity. 

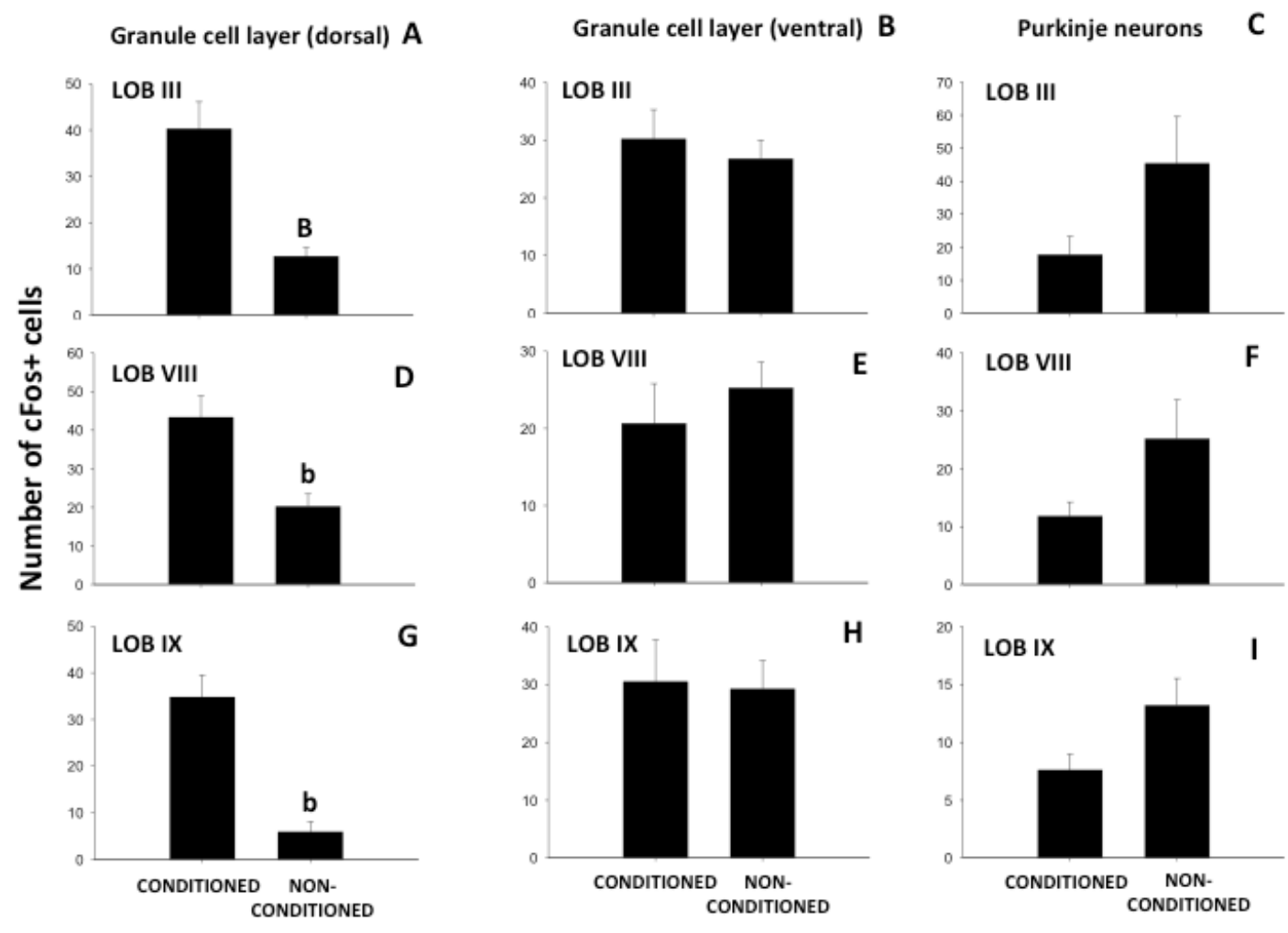

Figure 5. cFOS-IR in lobules III (A, B, C), VIII (D, E, F) and IX (G, H, I) of the conditioned and non-conditioned groups. Panels showed mean $\pm(\mathrm{SEM})$ of the number of $\mathrm{cFOS}+$ neurons in the dorsal $(\mathrm{A}, \mathrm{D}, \mathrm{G})$ and medial $(\mathrm{B}, \mathrm{E}, \mathrm{H})$ regions of the granule cell layer. Panels $(\mathrm{C}, \mathrm{F}, \mathrm{I})$ represent mean $\pm(\mathrm{SEM})$ of cFOS+ Purkinje cells. Capital letters indicate a significant difference $(\mathrm{p}<0.01)$ towards the conditioned group (B). Minor letters indicate a significant difference $(\mathrm{p}<0.05)$ towards the conditioned group $(b)$.

\section{3.cFOS-IR in Purkinje cells}

cFOS staining in Purkinje cells, the main target of the granule cell output through the parallel fibers, was initially evaluated by comparing the three experimental groups. A series of ANOVAs revealed a group effect that was restricted to the posterior lobules VIII, IX and X, each one of them displaying a characteristic pattern of results. Thus, in lobule VIII, the group effect $\left[\mathrm{F}_{2,13}=7.02, \mathrm{p}<0.01\right]$ was mainly the result of a reduction in the number of $\mathrm{cFOS}+$ neurons in the unpaired group (mean \pm SEM: $3.16 \pm 1.49$ ), which was lower than that observed in the conditioned $(11.80 \pm 2.45, \mathrm{p}<0.01)$ and saline $(9.06 \pm 0.80, \mathrm{p}<0.05)$ groups. On the other hand, in lobule IX the group effect $\left[\mathrm{F}_{2,13}=4.21, \mathrm{p}<0.05\right]$ was due to a significant increase in the 
number of cFOS + neurons in the conditioned group $(7.60 \pm 1.39)$ as compared to the unpaired $(3.83 \pm 1.10)$ and saline $(3.75 \pm 1.11)$ groups (Figure 4C, F, I). Finally, in lobule X, the group effect $\left[\mathrm{F}_{2,13}=13.51, \mathrm{p}<0.01\right]$ was probably a consequence of cocaine treatment, as it reflected a significant $(\mathrm{p}<0.01)$ increase in cFOS staining levels for the unpaired $(13.38 \pm 2.32)$ and conditioned $(11.20 \pm 1.38)$ groups versus those observed in the saline-treated mice $(1.25 \pm 0.73)$. In a second stage, we estimated cFOS-IR in Purkinje neurons in the conditioned and nonconditioned groups (Figure 5C, F, I). We did not observe any difference in Purkinje cells apart from lobule VII $\left(\mathrm{T}_{8}=-2.69, \mathrm{p}<0.05\right)$, where non-conditioned animals showed higher number of cFOS+ Purkinje cells.

\section{4.cFOS-IR in the olivary complex, pontine nuclei and the medial nucleus of the cerebellum}

Having confirmed the existence of a different pattern of cFOS expression in the conditioned and unpaired groups, we extended our cFOS analysis to the brainstem nuclei that involve the two major input sources to the parallel fiber-Purkinje ensemble (Figure 6). Thus, we included the pontine nuclei (Figure 6A, D) (which is the origin of the mossy fibers providing excitatory input to the granule cells) and the olivary complex (Figure 6B, E) (source of climbing fibers excitatory inputs reaching Purkinje cells). Also, we assessed cFOS-IR in the medial nucleus (Figure 6C, F) considered the main destination of Purkinje cells' axons in the vermis and reciprocally connected to the pontine and olivary nuclei. As summarized in table 3 , separate ANOVAs revealed the existence of statistically significant differences between groups in all these structures. More specifically, we observed that the unpaired group exhibited a significant increase in the number of cFOS + cells as compared to the conditioned and saline groups ( $<<0.01$ in all cases).

cFOS expression in the mossy and climbing fiber inputs to the cerebellum as well as in the medial nucleus was similar in the conditioned and the non-conditioned groups. No significant differences arose from Student t-test when comparing these two groups. 

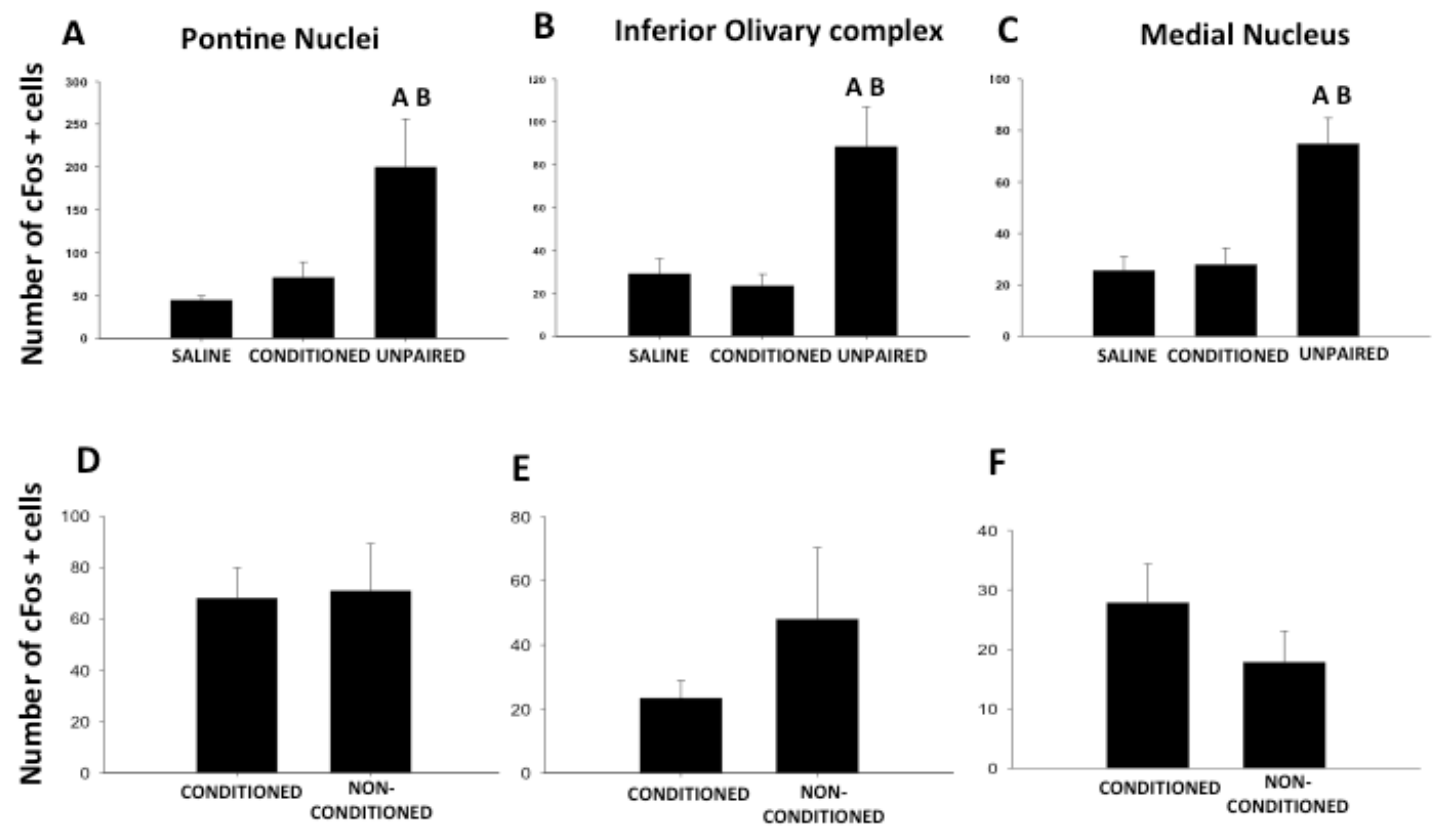

Figure 6. cFOS-IR in the pontine nucleus (A, D); the olivary complex (B, E) and the medial nucleus $(\mathrm{C}, \mathrm{F})$. Panels $\mathrm{A}, \mathrm{B}$ and $\mathrm{C}$ depict the results in the saline, conditioned and unpaired groups. Panels D, E and F showed cFOS expression in the conditioned and non-conditioned groups. Data are expressed as mean $\pm(\mathrm{SEM})$ of the number of $\mathrm{cFOS}+$ neurons in the ROIs evaluated. Capital letters indicate a significant difference $(\mathrm{p}<0.01)$ towards the saline $(A)$, or conditioned (B), respectively.

\subsection{Effect sizes}

Trying to sort out everything between group differences by their relative relevance, we decided to calculate their respective effect sizes by means of the Cohen's $d$ statistic. The results of these estimations are summarized in table 4, 5,6 and 7. Of note, in almost all cases analysed, $d$ values were higher than $/ 2$ / for those effects showing significant differences. In this regard, according to Cohen's own proposal [28], $d$ values higher than 0.8 (or lower than -0.8) are considered as "large effects", although this and other similar benchmarks must be viewed with caution [29]. To obtain a valid indication of the precision of these estimates, we also calculated the standard errors and $95 \%$ confidence intervals $(\mathrm{CI})$ corresponding to each one of these effects.

Remarkably, in several cases, the lower limit of the $95 \%$ CI corresponding to positive differences (increases) or the upper limit of the $95 \%$ CI corresponding to negative differences 
(decreases) still yielded $d$ values $>0.8$ or $<-0.8$, respectively. That is, a substantial proportion of the between-groups differences identified in the present study should be considered as "large effects" even though we used a more conservative estimation of the effect size.

\subsection{Correlational analysis}

Interestingly, most of the largest $d$ estimates were found on the comparisons involving the lobules III, VIII and IX, in particular at the level of the dorsal and ventral regions of the granule cell layer. As this and other observations seem to point out these lobules as especially relevant for reacting to cocaine-paired cues, we decided to investigate the reciprocal correlations between the levels of cFOS-IR observed in the different cerebellar regions. Thus, coupling the known anatomical connections and the obtained correlational values, we built up three separate working models that summarize the interrelationships between all the components of this cerebellar circuit as well as towards the preference for the cocaine-paired odour. These models are displayed in the Figures 7 and 8 commented on in further detail in the discussion section. 


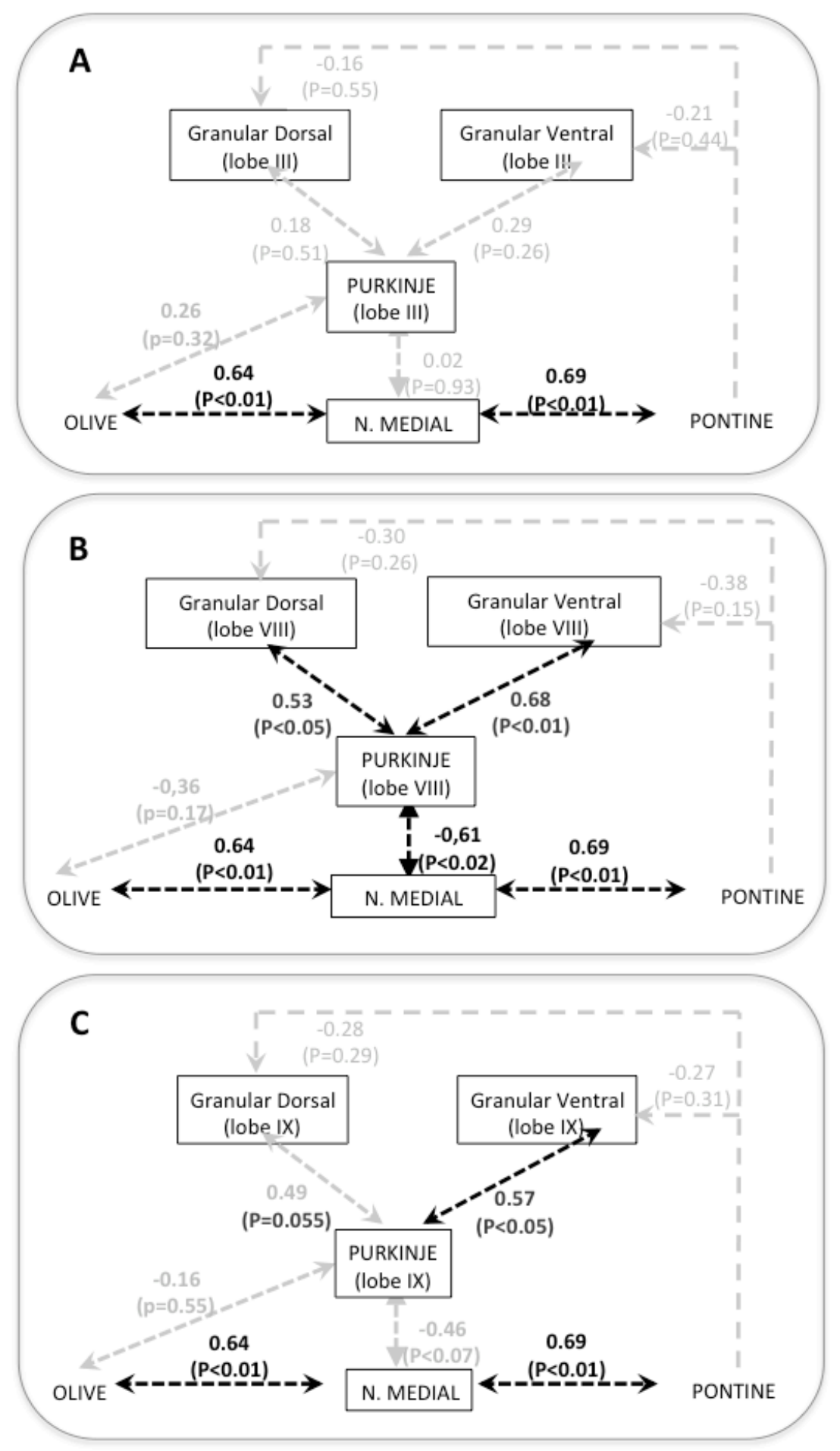

Figure 7. Correlation matrices among the levels of cFOS-IR found in different regions of the cerebellar cortex in lobule III (A); lobule VIII (B); lobule IX (C) and other anatomical regions of interest (ROIs). Dotted lines connect pairs of ROIs in which correlation was analysed through the Spearman's Rho index (black lines $\mathrm{p} \leq 0.05$, grey lines $\mathrm{p}>0.05$ ). 


\section{Discussion}

Our earlier findings involved the vermis cerebellum in the preference memory towards an odour-cue paired with repeated cocaine administrations [21]. Here, we extend the analysis to inputs and outputs of the vermis circuitry in order to draw a wider picture of the involvement of the cerebellum in preference towards a cue that predicts availability of cocaine. Meaningfully, preference towards a cocaine-paired odour and contingency during training induced a different pattern of cFOS-IR (Figure 9). As we previously observed [21], the cerebellar signature of conditioned preference was an increased expression of cFOS in the dorsal region of the granule cell layer of the cerebellar vermis. This enhanced cFOS expression was not seen when contingent training was provided to animals that did not become conditioned (the non-conditioned group). Neither was it seen when odour-cocaine pairings were not contingent as both stimuli were randomly presented (the unpaired group). Moreover, the lack of a contingent relationship between CS and US was specifically associated to a reduced expression of cFOS in the dorsal and ventral regions of the granule cell layer in several lobules, including the lobules VIII and IX. Therefore, a reduction in the neuronal activity of the granule cell layer may be tentatively regarded as a part of the hallmarks associated with lack of contingency in the relationship between CS-US.

Less clear is the association between the expression of preference towards a cocaine-associated cue and the cFOS-IR in Purkinje cells. Nevertheless, such association was seen in lobule VIII. It is also in this lobule where we observed a significant correlation between cFOS expression at the granule cell layer and that observed in Purkinje neurons. Furthermore, the number of activated Purkinje cells in lobule VIII was inversely correlated with that at the medial deep nucleus, supporting an inhibitory Purkinje modulation over the deep cerebellar neurons (Figure 7B). 
A

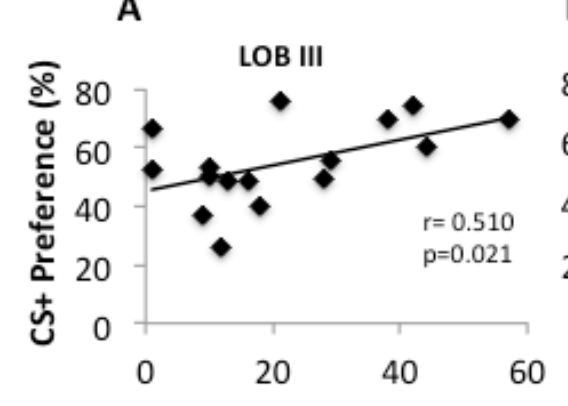

B

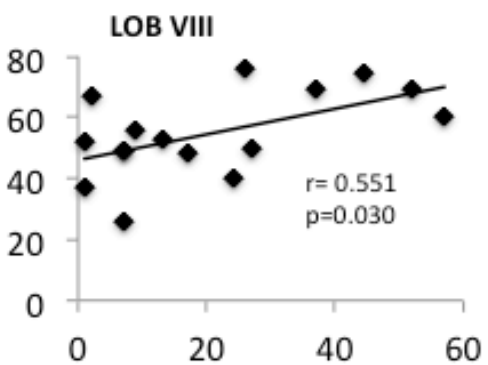

C

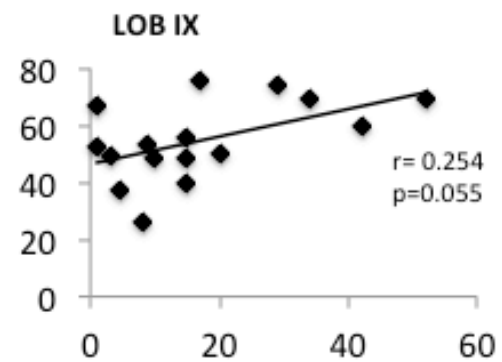

Number of cFos+ neurons in the dorsal region of the granule cell layer

D

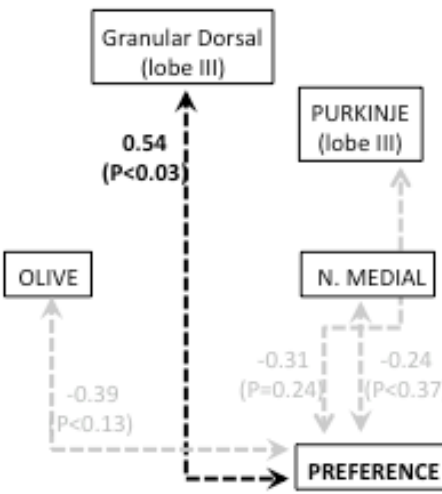

$\mathrm{E}$

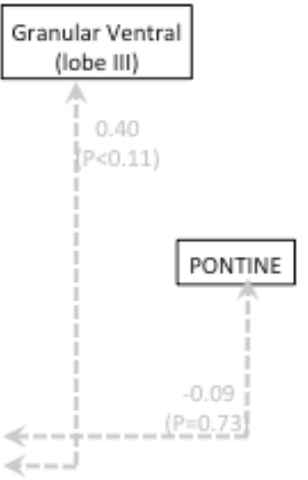

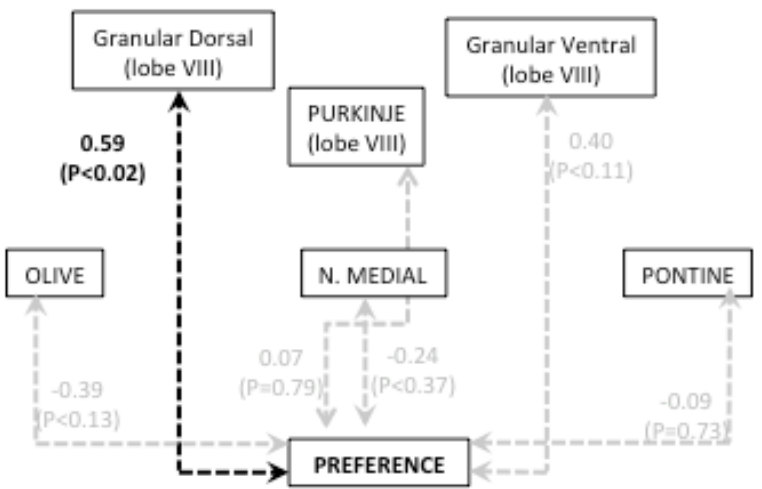

Figure 8. Panels A, B and C show correlations between the levels of cFOS-IR observed in the granule cell layer and the preference exhibited for the CS+ on the test day. Panels D and E depict correlation matrices among the levels of cFOS-IR found in the anatomical regions of interest (ROIs) and the preference exhibited for CS+ on the test day. Dotted lines were used to illustrate each one of the performed correlations using the Spearman's Rho index (black lines $\mathrm{p} \leq 0.05$, grey lines $\mathrm{p}>0.05$ ).

Extending our assessment to an unprecedented analysis, we observed that cFOS levels at the olivary complex and pontine nuclei (which provide the principal inputs to the cerebellum) were raised in the unpaired group. Interestingly, the same result was found in the medial nucleus, the main cerebellar output from the vermis. As a matter of fact, cFOS expression levels at these three cerebellar areas were highly inter-correlated. The results suggest that neurons in the input and output nuclei of the cerebellum increase their activity when contingency between cues and cocaine is lacking and, therefore, the appropriate behavioural alternative for the on-going 
contextual situation is uncertain. This suggestion seems to be coherent with the role of the cerebellum in prediction about internal events related to external cues [31-33]. The cerebellum accomplishes prediction in order to trigger preparatory actions that involve neuronal readiness of the brain networks that are going to be needed for the upcoming events. It is a probabilistic task that requires previous learning [32]. Thus, it could be expected that as the relationship between external cues and internal events become more and more predictable, and behavioural reactions are progressively more properly tuned to environmental demands, the inputs might be progressively suppressed. It is known that deep nuclear neurons are able to induce a powerful GABAergic inhibition over the olivary complex [34-36], so climbing fibers could be inhibited once learning has been optimised and behaviour tuned to environmental demands [31]. In previous studies addressing the cerebellar role in conditioning, it has been established that conditioned (CS) and unconditioned stimuli (US) reach the cerebellum by two separate pathways [for a review, 8,37,38]. CS information arrives at the granule cell layer from cerebral cortices and other brain areas via mossy fibers originated in the pontine nuclei. In turn, granule cells send information to Purkinje dendrites via parallel fibers. Also, climbing fibers projecting from the inferior olive convey US information to Purkinje dendrites. In addition, climbing and mossy fibers send direct excitatory inputs to the deep nuclear neurons [39,40]. In the present protocol, we used two odours as CS. The vermis cerebellum has been found consistently activated during odour perception tasks [41-44]. It is known that an extended prefrontallimbic network sustains olfactory processing and memory [45] so odour information may reach the cerebellum throughout the pontine nuclei via mossy fibers. Unconditioned effects of cocaine are a more complex configuration of interoceptive and central stimuli. Thus, during conditioning US information could arrive at the cerebellum from both the pontine nuclei and the inferior olivary complex. Importantly, the cerebellum connects anatomically and functionally to the circuitry responsible for acquiring, maintaining and expressing drug induced conditioned memories $[14,18,19,20,46,48]$. Specifically, the posterior vermis has been identified as the "limbic cerebellum" acting as an interface area between sensorimotor circuitry and emotional neural systems $[8,18,20,47]$ 
Moreover, cocaine may act locally in the cerebellum and trigger in situ aberrant plasticity [27].

Indeed, dopamine transporter (DAT) and receptors have been repeatedly described in the cerebellar cortex and deep nuclei $[9,10,13,15,20]$. As a further matter, we previously observed enhanced DAT levels in the granule cell layer of the animals exhibiting preference for cocainepaired cues [21].

Overall, the differences seen when comparing the three cocaine-treated groups lead us to suggest that the observed cerebellar pattern of neuronal activity resulted from plasticity reorganization in the cerebellar circuitry associated with memory induced by cocaine. Herein, although highly speculative at the moment, our findings point to the possibility that the dorsal region of the granule cell layer is the possible locus for the storage of conditioned emotional memory induced by cocaine. Notwithstanding, future causal research will be essential to elucidate the role of cerebellar areas in alterations leading to addiction-like behaviour as the present approach using c-FOS expression is not more than a correlational marker of neuronal activity.

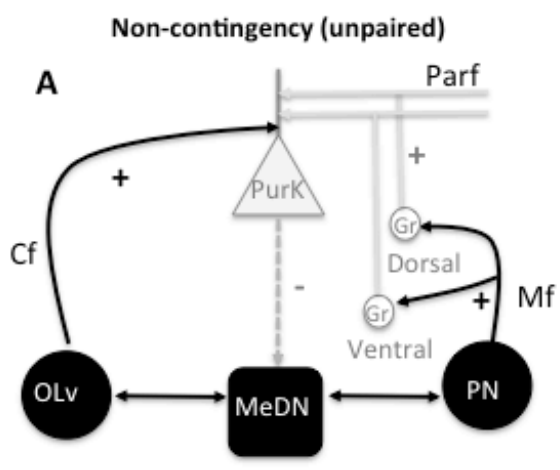

Preference for cocaine-associated cue (conditioned)

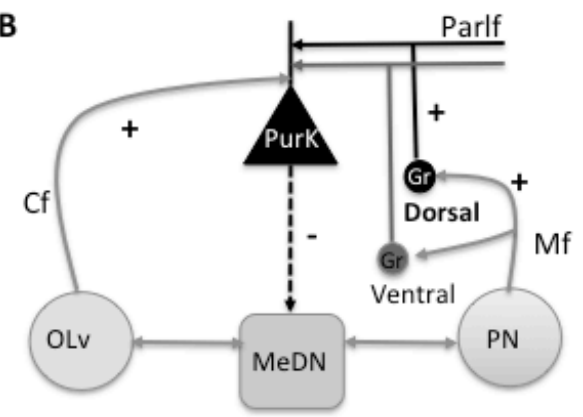

Non-preference (non-conditioned but paired)

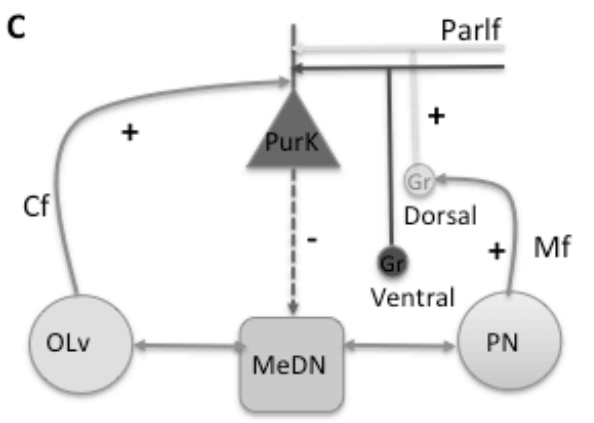


Figure 9. Working models depicting the present findings. (A) The lack of a contingent relationship between CS and US was associated with increased excitatory inputs to the cerebellum (climbing and mossy fibers) (black diagrams). In turn, this could lead to higher activity in the medial cerebellar nucleus. Also, the lack of contingency was featured by a reduced expression of cFOS in the dorsal and ventral regions of the granule cell layer (white diagrams). After contingent training (B), the hallmark of preference towards a cue paired with cocaine was a higher activity in neurons located at the dorsal region of the granule cell layer (black diagrams). In lobule VIII, in addition, cocaine-induced learning appeared to also be related to higher activity in Purkinje cells (black diagrams), which could induce an inhibitory control onto the medial nucleus activity. Despite contingent cue-cocaine associative training, there is a subgroup of animals that did not express preference for the cue paired with cocaine (C). In this case, we did not observe any of the signatures of cocaine-induced preference. Nonconditioned animals neither exhibited higher activity in the granule cell layer nor in Purkinje neurons. However, activity in the climbing and mossy excitatory inputs and in the deep medial nucleus remained similar to that of the group that develop preference for cocaine-associated cue.

\section{Acknowledgments}

This work was supported by grants and fellowships: Ministerio de Ciencia e Innovación [PSI2011- 29181]; FPU12/04059; FPI-PREDOC2009/05; PPF 2013 (13I087.01/1). Also we thank Timothy Attwood Gibbons for the English revision of the manuscript. 


\section{References}

[1] Everitt BJ, Robbins TW. Neural systems of reinforcement for drug addiction: from actions to habits to compulsion. Nature Neuroscience 2005;8:1481-9.

[2] Kalivas PW, Volkow ND. The neural basis of addiction: a pathology of motivation and choice. American Journal of Psychiatry 2005;162:1403-13.

[3] Hyman SE, Malenka RC, Nestler EJ. Neural mechanisms of addiction: the role of rewardrelated learning and memory. Annual Review of Neuroscience 2006;29:565-98.

[4] Robinson TE, Berridge KC. The incentive sensitization theory of addiction: some current issues. Review. Philosophical transactions of the Royal Society of London. Series B, Biological sciences 2008;363:3137-46.

[5] Belin D, Everitt BJ. Cocaine-seeking habits depend upon dopamine-dependent serial connectivity linking the ventral with the dorsal striatum. Neuron 2008;57:432-41.

[6] Volkow ND, Wang GJ, Tomasi D, Baler RD. Unbalanced neuronal circuits in addiction. Current Opinion in Neurobiology 2013;23:639-48.

[7] Sacchetti B, Baldi E, Lorenzini CA, Bucherelli C. Cerebellar role in fear conditioning consolidation. Proceedings of the National Academy of Sciences of the United States of America 2002;99:8406-11.

[8] Strata P, Scelfo B, Sacchetti B. Involvement of cerebellum in emotional behavior. Physiology Research 2011;60:S39-48.

[9] Panagopoulos NT, Papadopoulos GC, Matsokis NA. Dopaminergic innervation and binding in the rat cerebellum. Neuroscience Letters 1991;130:208-12.

[10] Ikai Y, Takada M, Shinonaga Y, Mizuno N. Dopaminergic and nondopaminergic neurons in the ventral tegmental area of the rat project, respectively, to the cerebellar cortex and deep cerebellar nuclei. Neuroscience 1992;51:719-28.

[11] Hoover JE, Strick PL. The organization of cerebellar and basal ganglia outputs to primary motor cortex as revealed by retrograde transneuronal transport of herpes simplex virus type 1 . Journal of Neuroscience 1999;19:1446-63.

[12] Ichinohe N, Mori F, Shoumura K. A di-synaptic projection from the lateral cerebellar nucleus to the laterodorsal part of the striatum via the central lateral nucleus of the thalamus in the rat. Brain Research 2000;880:191-7.

[13] Melchitzky DS, Lewis DA. Tyrosine hydroxylase- and dopamine transporter immunoreactive axons in the primate cerebellum. Evidence for a lobular- and laminar-specific dopamine innervation. Neuropsychopharmacology 2000;22:466-72.

[14] Hoshi E, Tremblay L, Féger J, Carras PL, Strick PL. The cerebellum communicates with 
the basal ganglia. Nature Neuroscience 2005;8:1491-3.

[15] Glaser PE, Surgener SP, Grondin R, Gash CR, Palmer M, Castellanos FX, Gerhardt GA. Cerebellar neurotransmission in attention-deficit/hyperactivity disorder: does dopamine neurotransmission occur in the cerebellar vermis? Journal of Neuroscience Methods 2006;151:62-7.

[16] Akkal D, Dum RP, Strick PL. Supplementary motor area and presupplementary motor area: targets of basal ganglia and cerebellar output. Journal of Neuroscience 2007;27:10659-73.

[17] Yu H, Sternad D, Corcos DM, Vaillancourt DE. Role of hyperactive cerebellum and motor cortex in Parkinson's disease. Neuroimage 2007;35:222-33.

[18] Bostan AC, Dum RP, Strick PL. Cerebellar networks with the cerebral cortex and basal ganglia. Trends Cogn Sci 2013;17:241-54.

[19] Snider RS, Maiti A. Cerebellar contributions to the Papez circuit. Journal of Neuroscience Research 1976;12:133-46.

[20] Schweighofer N, Doya K, Kuroda S. Cerebellar aminergic neuromodulation: towards a functional understanding. Brain Research Reviews 2004;44:103-16.

[21] Carbo-Gas M, Vazquez-Sanroman D, Aguirre-Manzo L, Coria-Avila GA, Manzo J, Sanchis-Segura C, Miquel M. Involving the cerebellum in cocaine-induced memory: pattern of cFos expression in mice trained to acquire conditioned preference for cocaine. Addiction Biology 2014;19:61-76.

[22] Grant S, London ED, Newlin DB, Villemagne VL, Liu X, Contoreggi C, Phillips RL, Kimes AS, Margolin A. Activation of memory circuits during cue elicited cocaine craving. Proceedings of the National Academy of Sciences of the United States of America 1996;93: $12040-5$.

[23] Schneider F, Habel U, Wagner M, Franke P, Salloum JB, Shah NJ, Toni I, Sulzbach C, Hönig K, Maier W, Gaebel W, Zilles K. Subcortical correlates of craving in recently abstinent alcoholic patients. American Journal of Psychiatry 2001;158:1075-83.

[24] Bonson KR, Grant SJ, Contoreggi CS, Links JM, Metcalfe J, Weyl HL, Kurian V, Ernst M, London ED. Neural systems and cue-induced cocaine craving. Neuropsychopharmacology 2002;26:376-86.

[25] Volkow ND, Wang GJ, Ma Y, Fowler JS, Zhu W, Maynard L, Telang F, Vaska P, Ding YS, Wong C, Swanson JM. Expectation enhances the regional brain metabolic and the reinforcing effects of stimulants in cocaine abusers. Journal of Neuroscience 2003;23:11461-8.

[26] Anderson CM, Maas LC, Frederick BdB, Bendor JT, Spencer TJ, Livni E, Lukas SE, Fischman AJ, Madras BK, Renshaw PF, Kaufman MJ. Cerebellar vermis involvement in cocaine-related behaviors. Neuropsychopharmacology 2006;31:1318-26. 
[27] Miquel M, Toledo R, García LI, Coria-Avila GA, Manzo J. Why should we keep the cerebellum in mind when thinking about addiction?. Current Drug Abuse Reviews 2009;2:2640 .

[28] Paxinos G, Franklin KBJ. The Mouse Brain in Stereotaxic Coordinates. 3rd ed. San Diego: Academic Press. 2008.

[29] Nakagawa S, Cuthill IC. Effect size, confidence interval and statistical significance: a practical guide for biologists. Biological Reviews 2007;82:591-605.

[30] Cohen J. Statistical Power Analysis for the Behavioral Sciences. 2nd ed. Hillsdale, NJ: Lawrence Erlbam Associates. 1988.

[31] Sears LL, Steinmetz JE. Dorsal accessory inferior olive activity diminishes during acquisition of the rabbit classically conditioned eyelid response. Brain Res 1991;545:114-22.

[32] Courchesne E, Allen G. Prediction and preparation, fundamental functions of the cerebellum. Learn Mem 1997;1:1-35.

[33] D'Angelo E, Casali S. Seeking a unified framework for cerebellar function and dysfunction: from circuit operations to cognition. Front Neural Circuits 2013;6:116.

[34] Lang EJ, Sugihara I, Llinás R. GABAergic modulation of complex spike activity by the cerebellar nucleoolivary pathway in rat. J Neurophysiol 1996;76:255-75.

[35] Bazzigaluppi P, Ruigrok T, Saisan P, De Zeeuw CI, De Jeu M. Properties of the nucleoolivary pathway: an in vivo whole-cell patch clamp study. PLoS One 2012;9.

[36] Schweighofer N, Lang EJ, Kawato M. Role of the olivo-cerebellar complex in motor learning and control. Front Neural Circuits 2013;7:94.

[37] Thompson RF, Steinmetz JE. The role of the cerebellum in classical conditioning of discrete behavioral responses. Neuroscience 2009;162:732-55.

[38] Freeman JH, Steinmetz AB. Neural circuitry and plasticity mechanisms underlying delay eyeblink conditioning. Learn Mem 2011;18:666-77.

[39] Ruigrok TJ. Cerebellar nuclei: the olivary connection. Prog Brain Res 1997;114:167-92.

[40] Ruigrok TJ, Voogd J. Organization of projections from the inferior olive to the cerebellar nuclei in the rat. J Comp Neurol 2000;426:209-28.

[41] Sobel N, Prabhakaran V, Hartley CA, Desmond JE, Zhao Z, Glover GH, Gabrieli JD, Sullivan EV. Odorant-induced and sniff-induced activation in the cerebellum of the human. J Neurosci 1998;18:8990-9001.

[42] Boyett-Anderson JM, Lyons DM, Reiss AL, Schatzberg AF, Menon V. Functional brain imaging of olfactory processing in monkeys. Neuroimage 2003;20:257-64. 
[43] Mainland JD, Johnson BN, Khan R, Ivry RB, Sobel N. Olfactory impairments in patients with unilateral cerebellar lesions are selective to inputs from the contralesional nostril. $\mathrm{J}$ Neurosci 2005;25:6362-71.

[44] Iannilli E, Bitter T, Gudziol H, Burmeister HP, Mentzel HJ, Chopra AP, Hummel T. Differences in anosmic and normosmic group in bimodal odorant perception: a functional-MRI study. Rhinology 2011;49:458-63.

[45] Tronel S, Sara SJ. Mapping of olfactory memory circuits: region-specific c-fos activation after odor-reward associative learning or after its retrieval. Learn Mem 2002;3:105-11.

[46] Heath RG, Dempesy CW, Fontana CJ, Myers WA (1978) Cerebellar stimulation: effects on septal region, hippocampus, and amygdala of cats and rats. Biol Psychiatry 1978; 13: 501-529.

[47] Turner BM, Paradiso S, Marvel CL, Pierson R, Boles Ponto LL, Hichwa RD \& Robinson RG. The cerebellum and emotional experience. Neuropsychologia 2007; 45: 1331-1341.

[48] Zhu L, Sacco T, Strata P, Sacchetti B (2011) Basolateral amygdala inactivation impairs learning-induced long-term potentiation in the cerebellar cortex. PLoS One 2011; 6: e16673. 
Tables

\begin{tabular}{|c|c|c|c|c|c|}
\cline { 2 - 6 } \multicolumn{1}{c|}{ Lobule II } & $15.20 \pm 2.81$ & $32.56 \pm 3.87^{\mathbf{A , C}}$ & $12.17 \pm 4.51$ & 7.71 & $\mathbf{\text { Cnpaired }}$ \\
\hline Lobule III & $11.60 \pm 3.17$ & $40.33 \pm 5.80^{\mathbf{A , C}}$ & $13.00 \pm 5.28$ & 10.22 & $<0.002$ \\
\hline Lobule V & $14.80 \pm 3.33$ & $36.60 \pm 4.78^{\mathbf{A , C}}$ & $12.33 \pm 5.76$ & 7.20 & $<0.007$ \\
\hline Lobule VI & $16.60 \pm 2.50$ & $39.20 \pm 4.74^{\mathbf{A , C}}$ & $9.69 \pm 4.09$ & 15.19 & $<0.001$ \\
\hline Lobule VII & $18.20 \pm 4.77$ & $36.20 \pm 3.00^{\mathbf{A , C}}$ & $6.50 \pm 3.10^{\mathbf{a}}$ & 17.01 & $<0.001$ \\
\hline Lobule VIII & $17.20 \pm 3.29$ & $43.34 \pm 5.48^{\mathbf{A , C}}$ & $4.33 \pm 1.54^{\mathbf{a}}$ & 30.87 & $<0.001$ \\
\hline Lobule IX & $16.80 \pm 3.15$ & $34.79+5.91$ & $5.09 \pm 2.22$ & 14.84 & $<0.001$ \\
\hline Lobule X & $12.00 \pm 1.79$ & $37.23 \pm 5.41^{\mathbf{A , C}}$ & $7.67 \pm 3.49$ & 17.08 & $<0.001$ \\
\hline
\end{tabular}

Table 1.- Descriptive statistics (mean+ SEM) and main outcomes of univariate ANOVAs assessing the levels of the c-Fos+ staining at the dorsal region of the granule cell layer in each cerebellar lobule. As can be seen, the treatment group factor had a significant effect on the number of c-Fos positive neurons in all. Capital letters indicate a significant difference $(\mathrm{p}<0.01)$ towards the saline $(A)$, conditioned $(B)$ or unpaired group (C). Lowercase letters indicate a significant difference $(\mathrm{p}<0.01)$ towards the saline (a), conditioned (b) or unpaired group (c). 


\begin{tabular}{|c|c|c|c|c|c|}
\cline { 2 - 6 } \multicolumn{1}{c|}{ Lobule II } & $26.4 \pm 4.08$ & $30.03 \pm 4.56$ & $10.16 \pm 3.22^{\mathbf{A , B}}$ & 15.60 & $\mathbf{\text { Unpaired }}$ \\
\hline Lobule III & $28.60 \pm 3.04$ & $30.18 \pm 5.07$ & $9.00 \pm 5.07^{\mathbf{A , B}}$ & 7.67 & $<0.006$ \\
\hline Lobule V & $19.6 \pm 2.37$ & $33.33 \pm 4.73^{\mathbf{a}}$ & $9.00 \pm 4.73^{\mathbf{B}}$ & 9.03 & $<0.003$ \\
\hline Lobule VI & $25.8 \pm 1.93$ & $33.56 \pm 4.47$ & $5.92 \pm 2.24^{\mathbf{A , B}}$ & 23.53 & $<0.001$ \\
\hline Lobule VII & $30.20 \pm 4.45$ & $35.48 \pm 6.03$ & $2.59 \pm 1.17^{\mathbf{A , B}}$ & 19.49 & $<0.001$ \\
\hline Lobule VIII & $27.80 \pm 6.46$ & $26.67 \pm 5.15$ & $1.66 \pm 0.91^{\mathbf{A , B}}$ & 11.48 & $<0.001$ \\
\hline Lobule IX & $21.40 \pm 4.14$ & $30.50 \pm 3.22$ & $3.33_{ \pm}+1.80^{\mathbf{A , B}}$ & 21.32 & $<0.001$ \\
\hline Lobule X & $23.00 \pm 1.22$ & $24.40 \pm 5.40$ & $6.83 \pm 3.09^{\mathbf{A , B}}$ & 7.71 & $<0.006$ \\
\hline
\end{tabular}

Table 2.- Descriptive statistics (mean \pm SEM) and main outcomes of univariate ANOVAs assessing the levels of the c-Fos + staining at the ventral region of the granule cell layer in each cerebellar lobule. As can be seen, the treatment group factor had a significant effect on the number of c-Fos positive neurons in all. Capital letters indicate a significant difference $(\mathrm{p}<0.01)$ towards the saline $(A)$, conditioned $(B)$ or unpaired group (C). Lowercase letters indicate a significant difference $(\mathrm{p}<0.01)$ towards the saline (a), conditioned (b) or unpaired group (c). 


\begin{tabular}{|c|c|c|c|c|c|}
\cline { 2 - 6 } \multicolumn{1}{c|}{} & Saline & Conditioned & Unpaired & $\mathbf{F}_{2,13}$ & $\mathbf{p}$ \\
\hline Pontine N & $44.37 \pm 5.05$ & $68.00 \pm 11.81$ & $199.83 \pm 56.66^{\mathbf{A , B}}$ & 5.14 & $<0.02$ \\
\hline I. Olive & $28.60 \pm 3.04$ & $23.40 \pm 5.28$ & $45.69 \pm 18.65^{\mathbf{A , B}}$ & 10.63 & $<0.001$ \\
\hline Medial N & $25.50 \pm 5.48$ & $27.80 \pm 6.52$ & $74.83 \pm 10.01^{\mathbf{A , B}}$ & 12.70 & $<0.001$ \\
\hline
\end{tabular}

Table 3.- Descriptive statistics (mean+ SEM) and main outcomes of univariate ANOVAs assessing the levels of the c-Fos+ staining in the brainstem nuclei and the medial deep nucleus. As can be seen, the treatment group factor had a significant effect on the number of c-Fos positive neurons in all of them. Capital letters indicate a significant difference $(p<0.01)$ towards the saline $(A)$, conditioned $(B)$ or unpaired group (C). 


\begin{tabular}{|c|c|c|c|c|}
\hline DORSAL & Cohen's d & SE & $\begin{array}{c}96 \% \text { CI } \\
\text { lower bound }\end{array}$ & $\begin{array}{l}96 \% \mathrm{Cl} \\
\text { upper } \\
\text { bound }\end{array}$ \\
\hline Lob II. Conditioned vs. Unpaired & 2.25 & 0.77 & 0.73 & 3.76 \\
\hline Lob II. Conditioned vs. Saline & 1.91 & 0.76 & 0.42 & 3.41 \\
\hline Lob III. Conditioned vs. Unpaired & 2.38 & 0.79 & $\mathbf{0 . 8 3}$ & 3.93 \\
\hline Lob III. Conditioned vs. Saline & 2.50 & 0.84 & 0.85 & 4.16 \\
\hline Lob V. Conditioned vs. Unpaired & 2.14 & 0.76 & 0.65 & 3.62 \\
\hline Lob V. Conditioned vs. Saline & 1.92 & 0.76 & 0.42 & 3.42 \\
\hline Lob VI. Conditioned vs. Unpaired & 3.24 & 0.92 & 1.44 & 5.04 \\
\hline Lob VI. Conditioned vs. Saline & 2.48 & 0.84 & $\mathbf{0 . 8 3}$ & 4.13 \\
\hline Lob VII. Conditioned vs. Unpaired & 3.52 & 0.96 & 1.63 & 5.42 \\
\hline Lob VII. Conditioned vs. Saline & 2.14 & 0.76 & 0.65 & 3.62 \\
\hline Lob VII. Unpaired vs. Saline & -1.39 & 0.67 & -2.71 & -0.07 \\
\hline Lob VIII. Conditioned vs. Unpaired & 4.71 & 1.17 & 2.41 & 7.01 \\
\hline Lob VIII. Conditioned vs. Saline & 3.16 & 0.95 & 1.30 & 5.02 \\
\hline Lob VIII. Unpaired vs. Saline & -1.55 & 0.69 & -2.91 & -0.20 \\
\hline Lob IX. Conditioned vs. Unpaired & 3.29 & 0.93 & 1.47 & 5.11 \\
\hline Lob IX. Conditioned vs. Saline & 1.99 & 0.77 & 0.48 & 3.51 \\
\hline Lob X. Conditioned vs. Unpaired & 3.35 & 0.94 & 1.51 & 5.18 \\
\hline Lob X. Conditioned vs. Saline & 2.85 & 0.90 & 1.09 & 4.62 \\
\hline \multicolumn{5}{|l|}{ VENTRAL } \\
\hline Lob II. Unpaired vs. Conditioned & -2.23 & 0.77 & -3.74 & -0.72 \\
\hline Lob II. Unpaired vs. Saline & -1.80 & 0.72 & -3.20 & -0.39 \\
\hline Lob III. Unpaired vs. Conditioned & -2.28 & 0.78 & -3.80 & -0.75 \\
\hline Lob III. Unpaired vs. Saline & -2.11 & 0.75 & -3.58 & -0.63 \\
\hline Lob V. Unpaired vs. Conditioned & -2.55 & 0.81 & -4.14 & -0.95 \\
\hline Lob V. Conditioned vs. Saline & 1.44 & 0.71 & 0.05 & 2.83 \\
\hline Lob VI. Unpaired vs. Conditioned & -3.98 & 1.04 & -6.03 & -1.94 \\
\hline Lob VI. Unpaired vs. Saline & -2.86 & 0.86 & -4.55 & -1.18 \\
\hline Lob VII. Unpaired vs. Conditioned & -3.47 & 0.96 & -5.35 & -1.60 \\
\hline Lob VII. Unpaired vs. Saline & -2.45 & 0.80 & -4.02 & -0.88 \\
\hline Lob VIII. Unpaired vs. Conditioned & -2.42 & 0.80 & -3.98 & -0.86 \\
\hline Lob VIII. Unpaired vs. Saline & -2.53 & 0.81 & -4.12 & -0.94 \\
\hline Lob IX. Unpaired vs. Conditioned & -3.85 & 1.02 & -5.85 & -1.85 \\
\hline Lob IX. Unpaired vs. Saline & -2.56 & 0.82 & -4.16 & -0.96 \\
\hline Lob X. Unpaired vs. Conditioned & -2.11 & 0.75 & -3.59 & -0.63 \\
\hline Lob X. Unpaired vs. Saline & -1.94 & 0.73 & -3.38 & -0.50 \\
\hline
\end{tabular}

Table 4.- Effect sizes of between-group differences found at the dorsal and ventral areas of the granular cell layer. Cohen's $d$ statistics, with its corresponding standard error (SE) and 96\% confidence intervals (CI) are provided. According to Cohen's own proposal, d values higher than 0.8 (or lower than -0.8) are considered as "large effects". Cases in which the lower limit of the $95 \%$ CI corresponding to positive differences 
(increases) or the upper limit of the $95 \% \mathrm{CI}$ corresponding to negative differences (decreases) yielded d values $>0.8$ or $<-0.8$ are highlighted (see text for further details). 


\begin{tabular}{|c|c|c|c|c|}
\hline & Cohen's d & SE & $\begin{array}{c}\mathbf{9 6 \% C} \\
\text { I } \\
\text { lower } \\
\text { bound }\end{array}$ & $\begin{array}{c}\text { 96\%CI } \\
\text { upper } \\
\text { bound }\end{array}$ \\
\hline PURKINJE & & & & \\
\hline Lob VIII. Conditioned vs. Unpaired & 2.20 & 0.77 & 0.70 & 3.70 \\
\hline Lob VIII. Unpaired vs. Saline & -1.50 & 0.68 & -2.84 & -0.16 \\
\hline Lob IX. Conditioned vs. Unpaired & 1.36 & 0.67 & 0.04 & 2.67 \\
\hline Lob IX. Conditioned vs. Saline & 1.38 & 0.70 & 0.00 & 2.76 \\
\hline Lob X. Conditioned vs. Saline & 2.47 & 0.84 & 0.82 & 4.11 \\
\hline Lob X. Unpaired vs. Saline & 3.13 & 0.90 & 1.37 & 4.90 \\
\hline $\begin{array}{c}\text { BRAINSTEM INPUTS AND } \\
\text { MEDIAL NUCLEUS }\end{array}$ & & & & \\
\hline N.Pontine. Unpaired vs. & 1.51 & 0.69 & 0.16 & 2.85 \\
\hline Conditioned & 1.78 & 0.71 & 0.38 & 3.18 \\
\hline Pontine N. Unpaired vs. Saline & 2.13 & 0.76 & 0.65 & 3.62 \\
\hline Olive N. Unpaired vs. Conditioned & 1.95 & 0.73 & 0.51 & 3.39 \\
\hline Olive N. Unpaired vs. Saline & 2.74 & 0.84 & 1.09 & 4.38 \\
\hline Medial N. Unpaired vs. Conditioned & 2.87 & 0.86 & 1.18 & 4.56 \\
\hline Medial N. Unpaired vs. Saline & 2.56 \\
\hline
\end{tabular}

Table 5.- Effect sizes of between-group differences found at Purkinje, cerebellar inputs and the medial nucleus. Cohen's d statistics, with its corresponding standard error (SE) and $96 \%$ confidence intervals (CI) are provided. According to Cohen's own proposal, $\mathrm{d}$ values higher than 0.8 (or lower than -0.8) are considered as "large effects". Cases in which the lower limit of the $95 \%$ CI corresponding to positive differences (increases) or the upper limit of the $95 \%$ CI corresponding to negative differences (decreases) yielded $\mathrm{d}$ values $>0.8$ or $<-0.8$ are highlighted. 


\begin{tabular}{|c|c|c|c|c|}
\hline DORSAL & Cohen's d & SE & $\begin{array}{c}96 \% \text { CI } \\
\text { lower bound }\end{array}$ & $\begin{array}{l}96 \% \text { CI upper } \\
\text { bound }\end{array}$ \\
\hline $\begin{array}{l}\text { Lob II. Conditioned vs. Non- } \\
\text { conditioned }\end{array}$ & 2.08 & 0.78 & 0.54 & 3.62 \\
\hline $\begin{array}{l}\text { Lob III. Conditioned vs. Non- } \\
\text { conditioned }\end{array}$ & 2.88 & 0.90 & 1.11 & 4.65 \\
\hline $\begin{array}{l}\text { Lob V. Conditioned vs. Non- } \\
\text { conditioned }\end{array}$ & 2.74 & 0.88 & 1.02 & 4.47 \\
\hline $\begin{array}{l}\text { Lob VI. Conditioned vs. Non- } \\
\text { conditioned }\end{array}$ & 1.53 & 0.71 & 0.12 & 2.94 \\
\hline $\begin{array}{l}\text { Lob VII. Conditioned vs. Non- } \\
\text { conditioned }\end{array}$ & 1.32 & 0.69 & -0.04 & 2.69 \\
\hline $\begin{array}{l}\text { Lob VIII. Conditioned vs. Non- } \\
\text { conditioned }\end{array}$ & 2.36 & 0.82 & 0.75 & 3.98 \\
\hline $\begin{array}{l}\text { Lob IX. Conditioned vs. Non- } \\
\text { conditioned }\end{array}$ & 2.03 & 0.77 & 0.50 & 3.55 \\
\hline $\begin{array}{l}\text { Lob X. Conditioned vs. Non- } \\
\text { conditioned }\end{array}$ & 2.48 & 0.84 & $\mathbf{0 . 8 3}$ & 4.13 \\
\hline \multicolumn{5}{|l|}{ MEDIAL } \\
\hline $\begin{array}{l}\text { Lob II. Conditioned vs. Non- } \\
\text { conditioned }\end{array}$ & 0.10 & 0.63 & -1.34 & 1.13 \\
\hline $\begin{array}{l}\text { Lob III. Conditioned vs. Non- } \\
\text { conditioned }\end{array}$ & 0.37 & 0.63 & -0.87 & 1.62 \\
\hline $\begin{array}{l}\text { Lob V. Conditioned vs. Non- } \\
\text { conditioned }\end{array}$ & 0.42 & 0.63 & -0.83 & 1.67 \\
\hline $\begin{array}{l}\text { Lob VI. Conditioned vs. Non- } \\
\text { conditioned }\end{array}$ & 0.54 & 0.64 & -0.71 & 1.80 \\
\hline $\begin{array}{l}\text { Lob VII. Conditioned vs. Non- } \\
\text { conditioned }\end{array}$ & 0.42 & 0.63 & -0.82 & 1.67 \\
\hline $\begin{array}{l}\text { Lob VIII. Conditioned vs. Non- } \\
\text { conditioned }\end{array}$ & 0.15 & 0.63 & -1.09 & 1.39 \\
\hline $\begin{array}{l}\text { Lob IX. Conditioned vs. Non- } \\
\text { conditioned }\end{array}$ & 0.23 & 0.63 & -1.00 & 1.47 \\
\hline $\begin{array}{l}\text { Lob X. Conditioned vs. Non- } \\
\text { conditioned }\end{array}$ & 0.01 & 0.63 & -1.24 & 1.23 \\
\hline
\end{tabular}

Table 6.- Effect sizes of between-group differences found at the dorsal and ventral areas of the granular cell layer when comparing the conditioned to the non-conditioned group. Cohen's d statistics, with its corresponding standard error (SE) and 96\% confidence intervals (CI) are provided. According to Cohen's own proposal, d values higher than 0.8 (or lower than -0.8) are considered as "large effects". Cases in which the lower limit of the $95 \%$ CI corresponding to positive differences (increases) or the upper limit of the $95 \%$ CI corresponding to negative differences (decreases) yielded d values $>0.8$ or $<-0.8$ are highlighted. 


\begin{tabular}{|c|c|c|c|c|}
\hline & Cohen's d & SE & $\begin{array}{l}96 \% C I \\
\text { lower } \\
\text { bound }\end{array}$ & $\begin{array}{l}96 \% \mathrm{CI} \\
\text { upper } \\
\text { bound }\end{array}$ \\
\hline \multicolumn{5}{|l|}{ PURKINJE } \\
\hline $\begin{array}{l}\text { Lob II. Conditioned vs. Non- } \\
\text { conditioned }\end{array}$ & -0.29 & 0.63 & -1.54 & 0.95 \\
\hline $\begin{array}{l}\text { Lob III. Conditioned vs Non- } \\
\text { conditioned }\end{array}$ & -1.15 & 0.68 & -2.49 & 0.18 \\
\hline $\begin{array}{l}\text { Lob V. Conditioned vs. Non- } \\
\text { conditioned }\end{array}$ & -0.84 & 0.66 & -2.14 & 0.44 \\
\hline $\begin{array}{l}\text { Lob VI. Conditioned vs. Non- } \\
\text { conditioned }\end{array}$ & -0.34 & 0.63 & -1.58 & 0.90 \\
\hline $\begin{array}{l}\text { Lob VII. Conditioned vs. Non- } \\
\text { conditioned }\end{array}$ & -1.70 & 0.73 & -3.15 & -0.25 \\
\hline $\begin{array}{l}\text { Lob VIII. Conditioned vs Non- } \\
\text { conditioned }\end{array}$ & -1.18 & 0.68 & -2.53 & 0.15 \\
\hline $\begin{array}{l}\text { Lob IX. Conditioned vs Non- } \\
\text { conditioned }\end{array}$ & -1.30 & 0.69 & -2.66 & 0.06 \\
\hline $\begin{array}{c}\text { Lob X. Conditioned vs Non- } \\
\text { conditioned }\end{array}$ & -0.41 & 0.63 & -1.66 & 0.84 \\
\hline \multicolumn{5}{|l|}{$\begin{array}{c}\text { BRAINSTEM INPUTS AND } \\
\text { MEDIAL NUCLEUS }\end{array}$} \\
\hline $\begin{array}{l}\text { N.Pontine.. Conditioned vs Non- } \\
\text { conditioned }\end{array}$ & -0.08 & 0.63 & -1.32 & 1.15 \\
\hline $\begin{array}{l}\text { Olive N. Conditioned vs Non- } \\
\text { conditioned }\end{array}$ & -0.68 & 0.65 & -1.95 & 0.59 \\
\hline $\begin{array}{l}\text { Medial N. Conditioned vs Non- } \\
\text { conditioned }\end{array}$ & 0.75 & 0.65 & -0.52 & 2.03 \\
\hline
\end{tabular}

Table 7.- Effect sizes of between-group differences found at Purkinje, cerebellar inputs and the medial nucleus when comparing the conditioned to the non-conditioned group. Cohen's d statistics, with its corresponding standard error (SE) and $96 \%$ confidence intervals (CI) are provided. According to Cohen's own proposal, d values higher than 0.8 (or lower than -0.8) are considered as "large effects". Cases in which the lower limit of the $95 \%$ CI corresponding to positive differences (increases) or the upper limit of the $95 \% \mathrm{CI}$ corresponding to negative differences (decreases) yielded $\mathrm{d}$ values $>0.8$ or $<$ 0.8 are highlighted in bold. 